\title{
Basic Concepts of Dairy Sire Selection ${ }^{1}$
}

\author{
Francisco Peñagaricano ${ }^{2}$
}

Sire selection is one of the most important decisions that a dairy producer makes. It represents a great opportunity to improve the profitability of the dairy production enterprise. Dairy bulls are genetically evaluated for several traits, including production, health, fertility, and type traits. This genetic information is regularly compiled and published as sire summaries. This fact sheet reviews some key concepts that should be considered in order to make proper selection decisions and discusses alternative methods for selecting sires based on multiple traits.

\section{The Basics of Sire Selection: Three Key Concepts}

There are at least three key concepts that appear in sire summaries that should be understood and considered in order to make proper sire selection decisions. These concepts are predicted transmitting ability, reliability, and percentile rank.

Predicted transmitting abilities, frequently known as PTAs, are the genetic predictions that should always be used when making sire selection decisions. PTA is an estimate of the relative genetic superiority or inferiority that a particular dairy bull will pass to its offspring for a given trait. It is important to note that the PTA value of one animal has no special meaning because PTAs are not absolute values. They are deviations from some preset value (the base) that is determined individually for each breed. However, PTAs are exceptional tools for comparing and ranking available bulls. In fact, the difference between the
PTAs of two animals is an estimate of the expected difference in the performance of their progeny. For instance, Table 1 shows PTAs for protein yield, productive life, and daughter pregnancy rate for two dairy bulls. Based on this information, we would expect that daughters of bull A would produce on average 12 more pounds of protein in 305 days than daughters of bull B. In addition, we would expect that an average daughter of bull A would survive 1 more month in the herd than an average daughter of bull B. Furthermore, we would expect that on average $0.5 \%$ more daughters of bull B will get pregnant in a 21-day period compared with daughters of bull A. It is important to note that only PTAs of animals evaluated within the same genetic evaluation can be compared.

Table 1. Predicted transmitting abilities (PTAs) for protein yield $(P Y)$, productive life $(\mathrm{PL})$, and daughter pregnancy rate (DPR) for two dairy bulls.

\begin{tabular}{|l|c|c|c|}
\hline \multicolumn{1}{|c|}{ Bulls } & PY (lb) & PL (mo) & DPR (\%) \\
\hline A & 45 & 4.0 & 1.8 \\
\hline B & 33 & 3.0 & 2.3 \\
\hline Difference & 12 & 1.0 & -0.5 \\
\hline
\end{tabular}

Reliability (REL or \%R) measures the accuracy or degree of confidence of a PTA. It is expressed as a percentage and it ranges from 1 to 99. Technically, it is defined as the squared correlation between the true transmitting ability and the predicted transmitting ability of a given animal. REL is a function of the heritability of the trait and the amount of information available for the animal; basically, as heritability and the amount of information increase, REL also increases. Therefore, a bull has a more reliable PTA

1. This document is AN337, one of a series of the Department of Animal Sciences, UF/IFAS Extension. Original publication date January 2018. Visit the EDIS website at http://edis.ifas.ufl.edu.

2. Francisco Peñagaricano, assistant professor, Department of Animal Sciences; UF/IFAS Extension, Gainesville, FL 32611.

The Institute of Food and Agricultural Sciences (IFAS) is an Equal Opportunity Institution authorized to provide research, educational information and other services only to individuals and institutions that function with non-discrimination with respect to race, creed, color, religion, age, disability, sex, sexual orientation, marital status, national origin, political opinions or affiliations. For more information on obtaining other UF/IFAS Extension publications, contact your county's UF/IFAS Extension office. 
for protein yield than for daughter pregnancy rate because protein yield has higher heritability. Similarly, a bull with many daughters has a more reliable PTA for any given trait than a bull with no or only a few daughters. Although we should not select or exclude potential sires based only on reliability, we can use REL values as a guide to decide how intensely we want to use a bull. For instance, we might choose to purchase 120 units of semen from a progenytested bull with 95\% REL, or we might choose to purchase 20 units of semen from each of 6 different young bulls with better genetic merit than the progeny-tested bull but only 70\% REL.

Percentile rank are tables or graphs of PTA distributions that provide useful information regarding the rank or position of a given bull within the population evaluated for a given trait of interest. The interpretation of the percentile rank is straightforward: if a bull ranks in the 95th percentile for a given trait, this means that the bull is genetically superior to $95 \%$ of all the evaluated bulls in its breed. Table 2 shows the percentile rank of PTAs for protein yield, productive life, and daughter pregnancy rate for progeny-tested AI Holstein bulls (official proofs from CDCB April 2017, https://www.uscdcb.com). Based on this table, we can see that bull A ranks in the top $5 \%$ for protein yield while bull B ranks in the top $20 \%$ of the bull population for this trait. Moreover, bull B ranks in the top 20\% for daughter pregnancy rate while bull A ranks in the top 50\% (its PTA for DPR is a little below the threshold of the 80th percentile).

Table 2. Percentile rank of PTAs for protein yield (PY), productive life $(\mathrm{PL})$, and daughter pregnancy rate (DPR) for progeny-tested Al Holstein bulls (data from April 2017).

\begin{tabular}{|l|c|c|c|}
\hline \multicolumn{1}{|c|}{ Percentile } & PY & PL & DPR \\
\hline 99th (top 1\%) & 56 & 7.4 & 4.7 \\
\hline 95th (top 5\%) & 44 & 6.0 & 3.4 \\
\hline 90th (top 10\%) & 39 & 5.1 & 2.7 \\
\hline 80th (top 20\%) & 31 & 4.2 & 1.9 \\
\hline 50th (top 50\%) & 18 & 2.1 & 0.3 \\
\hline
\end{tabular}

\section{Selecting Sires for Multiple Traits}

There are several traits, including production traits (such as milk yield and milk composition) and functional traits (such as longevity, fertility, udder health, and calving ability), that directly impact the profitability of the dairy enterprise. Sire selection represents an opportunity to genetically improve most of these relevant traits.

One simple method of multiple-trait selection is the use of independent culling or rejection levels. To use this method, we first have to choose minimum standards or cut-off values for each of the traits undergoing selection, and then we must select only those animals that simultaneously meet all these criteria. For example, we might decide that we will only use bulls with PTAs that are at least +41 for protein yield, +4.5 for productive life, and +2.7 for daughter pregnancy rate. Although this method is quite popular and allows us to select simultaneously for multiple traits using simple rules, it has some important limitations. First, the minimum standards or cut-off values are generally chosen without any formal approach. In addition, these threshold values may vary over time due to genetic progress and changes in the definition of the genetic base; therefore, cutoff values that are appropriate today may be too liberal or too restrictive in the near future. This method also ignores the genetic relationships between traits of interest, which adversely impacts the selection efficiency when selecting for genetically correlated traits. Finally, the effectiveness of the independent culling levels decreases rapidly as the number of traits under selection increases. As more traits are considered, fewer bulls simultaneously meet all the criteria. More importantly, it is likely these bulls are only marginally superior for each trait.

A better approach for selecting dairy sires for multiple traits is the use of an economic selection index. This method combines multiple traits of interest into a single value, greatly facilitating the identification of the best animals. Individual traits are weighted based on relevant genetic information, such as heritabilities and genetic correlations, and their economic importance. These economic weights are based on current prices for both inputs (e.g., feed and veterinary costs) and outputs (e.g., milk prices) of a dairy production enterprise. These values are updated regularly to reflect current trends in the price of feed and milk. Contrary to the method based on independent culling levels, selection indices perform well regardless of the number of traits under selection and allow for selection of animals that are superior for one trait and slightly deficient in other traits, which leads to the maximization of the selection response.

Currently, there are many selection indices available. The USDA-ARS Animal Improvement Programs Laboratory has developed four different economic selection indices for dairy cattle: Lifetime Net Merit (NM\$), Cheese Merit (CM\$), Fluid Merit (FM\$), and Grazing Merit (GM\$) (https://aipl.arsusda.gov). All of these indices simultaneously consider production traits (including milk, fat, and protein yield), female fertility traits (including daughter pregnancy rate, heifer conception rate, and cow conception rate), longevity (including productive life and livability), 
somatic cell score, functional type traits (including udder composite, feet and legs composite, and body size composite), and calving ability. Among these four indices, $\mathrm{NM} \$$ is probably the most popular index and represents the most appropriate breeding goal for the vast majority of US dairy farmers. Protein and fat yield receive the highest relative weights in NM\$, representing $18.3 \%$ and $23.7 \%$, respectively. Additionally, productive life has a relative weight of $13.4 \%$, which is the highest relative weight among the fitness traits. Female fertility traits, somatic cell score, and functional type traits receive relative weights of $9.7 \%, 6.5 \%$, and $16 \%$, respectively. Finally, calving ability (a sub-index that includes both service-sire and daughter calving ease and stillbirth), receives a relative weight of $4.8 \%$. Overall, $\mathrm{NM} \$$ has relative weights of $43 \%$ for production traits, $41 \%$ for health and fertility traits, and $16 \%$ for functional type traits.

Three alternative indices are available for producers with special milk markets or production systems. For dairy farmers who are paid mainly for milk components, the $\mathrm{CM} \$$ is probably the most appropriate index. This selection index places more emphasis on protein yield than the NM\$ index. Additionally, milk volume is more heavily penalized in $\mathrm{CM} \$$ compared with $\mathrm{NM} \$$, indicating that the selection for more milk solids should be achieved by improving fat and protein percentage instead of total milk yield. On the other hand, for dairy producers who are paid mainly for milk volume (milk markets where the incentives for milk components are insignificant), the FM\$ is probably the most appropriate breeding goal. This index has relative weights of $20.4 \%$ and $24.3 \%$ for milk and fat yield, respectively, and it has a relative weight of $0 \%$ for protein yield. Finally, pasture-based dairy producers may find the GM\$ index as the most convenient selection index. Compared to $\mathrm{NM} \$$, the GM\$ index places roughly the same emphasis on production traits, greater emphasis on fertility traits, and slightly less emphasis on productive life. Other selection indices are provided by the breed associations, such as Total Performance Index (TPI) by the Holstein Association and the Jersey Performance Index (JPI) by the American Jersey Association. These indices tend to put more emphasis on certain type traits and slightly less emphasis on some fitness traits.

\section{Summary}

Dairy sires should be selected carefully because they will have a great impact on the profitability of the dairy enterprise. Sire selection decisions should be based on PTA information, and the selection of sires for multiple traits should be based on economic selection indices. For most producers, the Net Merit is the most appropriate index. Remember to use the percentile rank to see how genetically superior a bull is compared to other available bulls, and the reliability (REL) value to properly manage the risk associated with imprecision in the estimate of genetic merit.

For more information, contact Francisco Peñagaricano at fpenagaricano@ufl.edu or call (352) 392-1981 ext. 231. 